\title{
The effect of Information and Communication Technologies on creativity in collaborative design
}

\author{
Vicente Chulvi, Elena Mulet, Francisco Felip, Carlos García-García
}

\begin{abstract}
This study compares the degree of creativity of forty-two conceptual designs proposed as solutions to two innovative design problems developed in face-to-face and virtual collaborative environments. The solutions obtained were evaluated by three experts applying the Moss metric, which considers the level of usefulness and the level of unusualness. The average values and the trends of the data were obtained and an analysis of the variance was also performed to determine whether the environment influences the degree of creativity. The results show that it cannot be proved that the level of creativity is influenced by working face-to-face or virtually, that is, whether Information and Communication Technologies (ICTs) are used or not has no effect on the final result.
\end{abstract}

Keywords : collaborative design, conceptual design, creativity and innovation, design groups, Information and Communication Technologies

\section{Introduction}

In a world based on interconnection and the continuous exchange of information, product design has evolved to be performed in a decentralized way. The progress in computation and real-time access to any content from anywhere around the world makes smooth collaboration between multidisciplinary teams possible. This results in the elimination of physical barriers and improving synergies between designer and industry. Hence, the development of the new Information and Communication Technologies (ICT) has led to a change in the way of working for society in general and for the design engineer in particular (Rahman et al. 2012). Now, the designers have the new technologies available for design assistance (Adenauer et al. 2013) and design engineer communication within project work (Regli 1997). For the last few decades, the design process could not be understood without the integration of the new technologies in all its phases - from idea conceptualization and formal research (Grabska 2012; Seichter 2003) to its transfer to industry (Groover and Zimmers 1983; Jezernik and Hren 2003; Yu et al. 1993). These points motivate that future engineers need to be trained in the use of ICT right from the academic stage of their preparation (Flowers 2001).

\subsection{Background}

One of the concepts that arouses most interest and concern in the field of virtual design teams is creativity, since it is considered one of the factors determining the success of the design outcomes. The wide range of methodologies oriented towards creativity is evidence of that fact (Gundy 1981; Jones 1980; Thompson and Lordan 1999), as is the huge number of scientific studies that analyse and compare the effect of creative methods, sketching and other stimuli during idea generation (Lopez-Mesa et al. 
2011; Thompson and Lordan 1999; Van der Lugt 2002) among others. MacGregor and Torres-Coronas (MacGregor and Torres-Coronas 2007) edited a collection of research articles on the topic of creativity stimulation in the field of virtual teams. This book proposes a set of solutions to avoid conflicts when working in virtual teams. The points where more research is needed are also identified, such as the search for evidence about what kinds of activities are adequate for working in virtual teams.

Studies conducted up to now evidence that the use of virtual design teams does not lessen creativity, but it in fact also seems to be encouraged by factors such as the kind of interaction or communication. Leenders (Leenders et al. 2003) focused on new product development team's communication pattern as a key factor of team creativity. The study analyzed the impact of three factors in the communication exercised during the development of electronic products: the team member proximity, the communication modality and the task structure. The paper concluded that the proximity of the team members in early stages of the work helps to achieve greater creativity, but if the task is highly complex, high levels of virtuality appear unproductive. Similarly, Kratzer (Kratzer et al. 2006) conducted a study with 44 research and design virtual teams, in order to analyze the factors that explain their creative performance. The study concluded that the performance achieved depended on the variability of similar factors: the physical proximity (the creative performance is higher for teams that are highly variable in physical proximity), the use of communication modalities (the creative performance is higher for teams that combines face-to-face and virtual communication) and the manner in which the task is coordinated (teams that carried out variable intra-team interdependencies achieved higher creativity). Thereby, observations in research groups working in electronic product development show that the virtuality of research and development teams is neither generally positive nor negative for their creative performance: the creative outcome is a function of how virtuality is managed in these teams. Moreover, several authors have developed new ICT-based tools that allow the interaction of a group of persons who are distributed during the creative phases of the design, and concluded that creativity can be enhanced by means of naturally sharing knowledge (Shigeki and Zafer 2008).

Previous work on asynchronous virtual teams concludes that, despite the fact that there are elements that complicate creativity, the chance to connect a huge number of people has great potential for establishing a collaborative environment that generates a creativity stimulation on its own (Ocker 2005). A more recent study demonstrates that distributed collaborative work produces better results in idea generation when teams work in a synchronous mode than when they do so in an asynchronous mode (Rahman et al. 2012). Regarding the university educational context, the use of virtual teams has been analysed in a practical experiment. Thirty-four students were asked to use Web 2.0 technologies, such as Wikideas and Creativity Connector tool, in a context of project-based learning. The study concluded that a positive influence on creativity is appreciated when these tools are used (Ardaiz-Villanueva et al. 2011). Moreover, several studies have been conducted to evaluate and compare virtual teams and face-to-face teams. Warkentin (Warkentin et al. 1997) analysed the effectiveness of a World Wide Web-based asynchronous computer conference system compared to traditional face to face meetings. Both teams had to perform some collaborative tasks and exchange information during the process. The study found out that virtual groups showed a lower level of cohesion and satisfaction with results than face-to-face groups, so the authors recommend combining virtual work with traditional meetings to strengthen the 
relationship of the working groups. Andres (2002) carried out a comparative study on virtual and face-toface work in software programmers, which concluded that face-to-face work is more productive, but there are no differences in levels of satisfaction. De Pillis (De Pillis and Furumo 2007) analysed the behaviour that students showed in a intellective task, divided into small virtual an face-to-face groups. Similarly, the conclusion was that the virtual teams displayed lower average performance than the face-to-face teams because they needed more time to complete the task. Additionally, the virtual teams showed less cohesion and satisfaction, due to a higher level of deadbeat members. More recently, Tang (Tang et al. 2011) performed a similar analysis in the field of design, by comparing design teams in traditional and digital environments when generating creative solutions. In his study, the digital environment tries to emulate the traditional one, so the designers worked together in a synchronous mode using audiovisual communication. Functionality and innovation were two of the parameters used to assess the outcomes of the experience. Conclusions suggest that the design process in both pen and paper and digital drawing environments does not show any significant differences.

Although many of the studies conducted in recent years seek to quantify the effectiveness of both ways of working, few have explored the impact that the different working tools have in the creativity degree of designer teams when facing conceptual product design. Moreover, most of the cited works emphasize the use of certain technology, but there are also few of them concerned about trying to compare the effect of the use of technology against not using it when the main point is not the technology by itself. In order to complement previous studies, a new study is proposed in this article with a particular use of technology for conceptual design, and with an appreciable number of cases whose allow to have a sample size to achieve better analysis conclusions. The present work aims to compare the level of creativity of the solutions to design problems presented by design teams each made up of three members when they work face-to-face or virtually. In the face-to-face mode, they work in the same place using paper and pencils, while in the virtual mode they use digital sketching tools and a shared synchronous document. In this last case, the designers work in separate rooms and they communicate through chat. As research results, the aim is to determine whether the conceptual solutions generated by the teams show higher, lower or similar levels of creativity when they have been working face-to-face or virtually. The starting hypothesis is that the creativity level will be similar in both cases because, despite the fact that virtual teams communicate only by chat, the expected team interaction efforts will be more focused on analysing and solving the design problem, so this will not cause a negative effect. Furthermore, the attention level achieved when reading the written information on the chat, which can be reread several times, is expected to be higher than when talking in a face-to-face group.

There are several metrics that can be used to assess the degree of creativity of the conceptual solutions for the innovative design problems, like Sarkar and Chakrabarti's SAPPhIRE (State change-Action-PartPhenomenon-Input-oRgan-Effect) model (Sarkar and Chakrabarti 2008), Besemer and O’Quin's taxonomy of CPSS (Creative Product Semantic Scale) (O'Quin and Besemer 1989), the rating questionnaires of Kudrowitz and Wallace (Kudrowitz and Wallace 2012), the metrics for measuring ideation effectiveness of Shah et al (2003) or the comparative scale of Moss (Moss 1966). This last one was chosen for the present study because it is specifically designed to assess creativity by comparing a set of solutions provided for the same problem, and it uses a continuous scale for this purpose, which is 
useful for statistical treatment. This metric assesses creativity as the combination of usefulness and unusualness, which is a common itemization of creativity used in creativity metrics for product design, and which produces similar results compared with previous ones, as is demonstrated in the study conducted by Chulvi (Chulvi et al. 2012). The study showed the evaluation of five objects by means of four different creativity assessment methods: Sarkar and Chakrabarti (2008), Moss (1966), EPI (Justel, 2006) and CPSS (O'Quin and Besemer 1989). There, CPSS is a questionnaire that comprises several evaluators and provides the creativity value in a continuous scale; the methods of Moss and EPI comprise one single evaluator and the results are in a continuous scale; and the method of Sarkar and Chakrabarti comprises one single evaluator and provides the creativity values as ordinal data. The study concludes that all four evaluation methods provide with similar results regarding to creativity

Moreover, the Moss scale has been used in several research works during more than four decades, so it is highly accepted metric for measuring creativity (Michel, 2001; Stricker, 2008; Smith, 2010; Chulvi et al, 2013; Sarkar and Chakrabarti, 2014).

\section{Methodology of the study}

\subsection{Description of the experiment}

Groups of three individuals were formed for the experiment. The subjects were students in the last year of their Design Engineering degree, so they all offered a similar profile and academic training. Design Engineering degree combine the learning of technical and creative subjects (Howard et al., 2008). Sixtysix students participated in the experiment, 25 males and 41 females, and were divided up into a total of 22 groups. The experiment was part of a practical class of their degree.

Each group was asked to solve two conceptual design problems during the experiment. In one of them they had to work in face-to-face groups and in the other one they were to work in virtual teams by using ICT. No guidance was given to them regarding the use of any design method, the aim being to avoid interferences, since one method could be more or less effective depending on the working mode. The problems chosen were related to the design of a new product that allows the automation of a function that has been performed manually up to now, and that could be commercialized in the domestic sphere. The teams where provided with the next problem statements in the corresponding experiment phase:

- $\quad$ Problem 1: design an automated domestic device to paint fingernails.

- Problem 2: design an automated domestic device to take the fishbone out of small and medium-sized fish.

\subsection{Materials and technologies}

For face-to-face working, the design groups were taken to a cubicle with abundant natural light and they were provided with drawing material for elaborating sketches and designs. A camera was placed in a corner of the room in order to record the design process, so that the way the team worked could be analysed in future studies. In the case of those working in virtual teams, each member of the team was led 
to a separate cubicle with a computer connected to the internet and equipped with flexible tablets with electronic pencils (Flexi Style Pixel, of NGS - www.ngs.eu) in order to make their working conditions and those of the face-to-face teams more similar. The collaborative drawing tool selected for this study is the one provided by Google Drive (Figure 1). The simplicity of this tool and its intuitive interface makes it suitable for a fast learning process. Moreover, the similarity with the Windows "Paint" application means that the students may already know several aspects and functions of the tool, since they are used to similar workspaces. This computer application provides them with a workspace comparable to the one used in face-to-face work, including the use of similar drawing resources (kind and width of lines, colours, text) and it also provides them with a chat application that allows the team members to communicate efficiently with one another. A screencast application was installed in the computers in order to capture what is happening on the screen, so the working process of virtual teams could also be archived. Table 1 resumes the working conditions, while Figure 2 shows an overview of the experimental settings:

9.

Dibuix sense títol

Fitxer Edita Visualitza Insereix Format Organitza Eines Taula Ajuda Shan desat tots els canvis a Drive

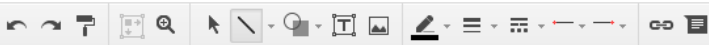

Figure 1. View of the Google Drive's collaborative drawing tool

Table 1. Conditions of the experiment

\begin{tabular}{|l|l|l|}
\hline & Face-to-face teams & Virtual teams \\
\hline Location & Common room & Separate rooms \\
\hline Communication & Direct communication & Chat \\
\hline Equipment / material & Broad table & Online computer \\
& DINA3 and DINA4 format sheets & Google Drive drawing tool \\
& Colour pencils and rubber & Flexible tablets with electronic pencils \\
\hline
\end{tabular}




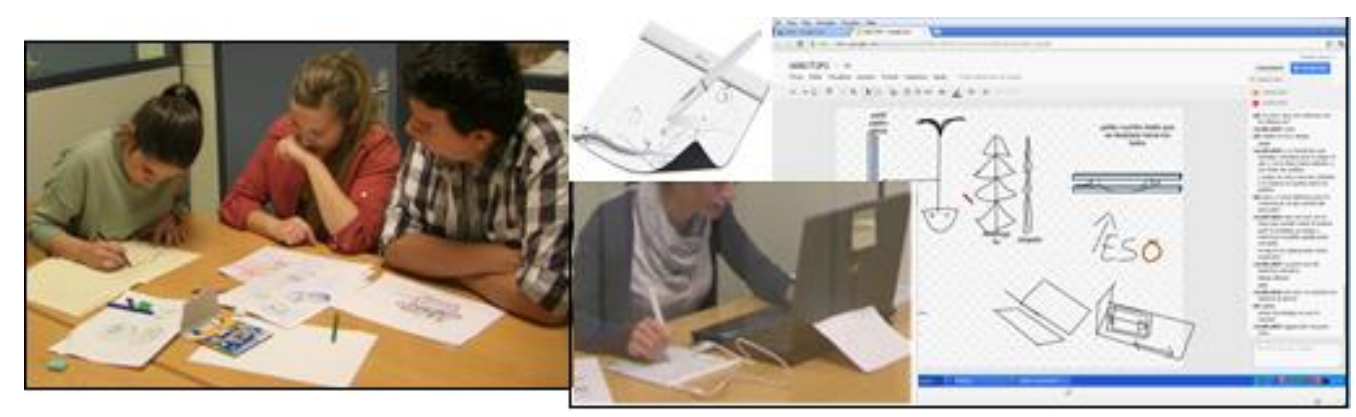

Figure 2. Experimental setting a) in face-to-face environment; b) in virtual environment

\subsection{Development of the experiment}

Twelve participants were called simultaneously in at random to conduct the initial training and carry out the experience. The experiment was performed in three phases with only five minutes of rest between them, as represented in Figure 2:

Phase 1 (30 minutes): preparation

In this phase the groups of 12 students were put together in the same room. At this stage they were taught about how the tools they were going to use during the experiment worked, and they were given a short time to become familiar with them. They were asked to draw anything using the drawing tool of Google Drive with the flexible tablets with electronic pencils, and later to use these tools with the student sitting at their side. At this point the participants did not know who their team mates were.

Phase 2 (50 minutes): problem solving 1

The 12 students were led to the cubicles, where they were divided up randomly into four teams of three students (Figure 3 ) and asked to solve a design problem. In order to avoid any interferences caused by the order of solving a problem or the use of a technology, half of the teams started with problem P1 and the other half with problem P2. Moreover, half of the teams that were beginning with each problem started to work in face-to-face groups and the other half started working in virtual groups (using ICT). So, in this phase there is a team working face-to-face which is solving problem P1; another team working face-toface which is solving problem P2; a team working in virtual groups which is solving problem P1; and a last team working in virtual groups which is solving problem P2. The assignment of tools and problems is shown in Table 2.

The schedule given for problem solving was as follows:

- Time for reading the problem statement and asking moderators about any doubts: 5 ,

- Problem solving: $30^{\prime}$

- Time for documenting the final result: $10^{\text {, }}$ 
Table 2. Distribution in phases 2 and 3

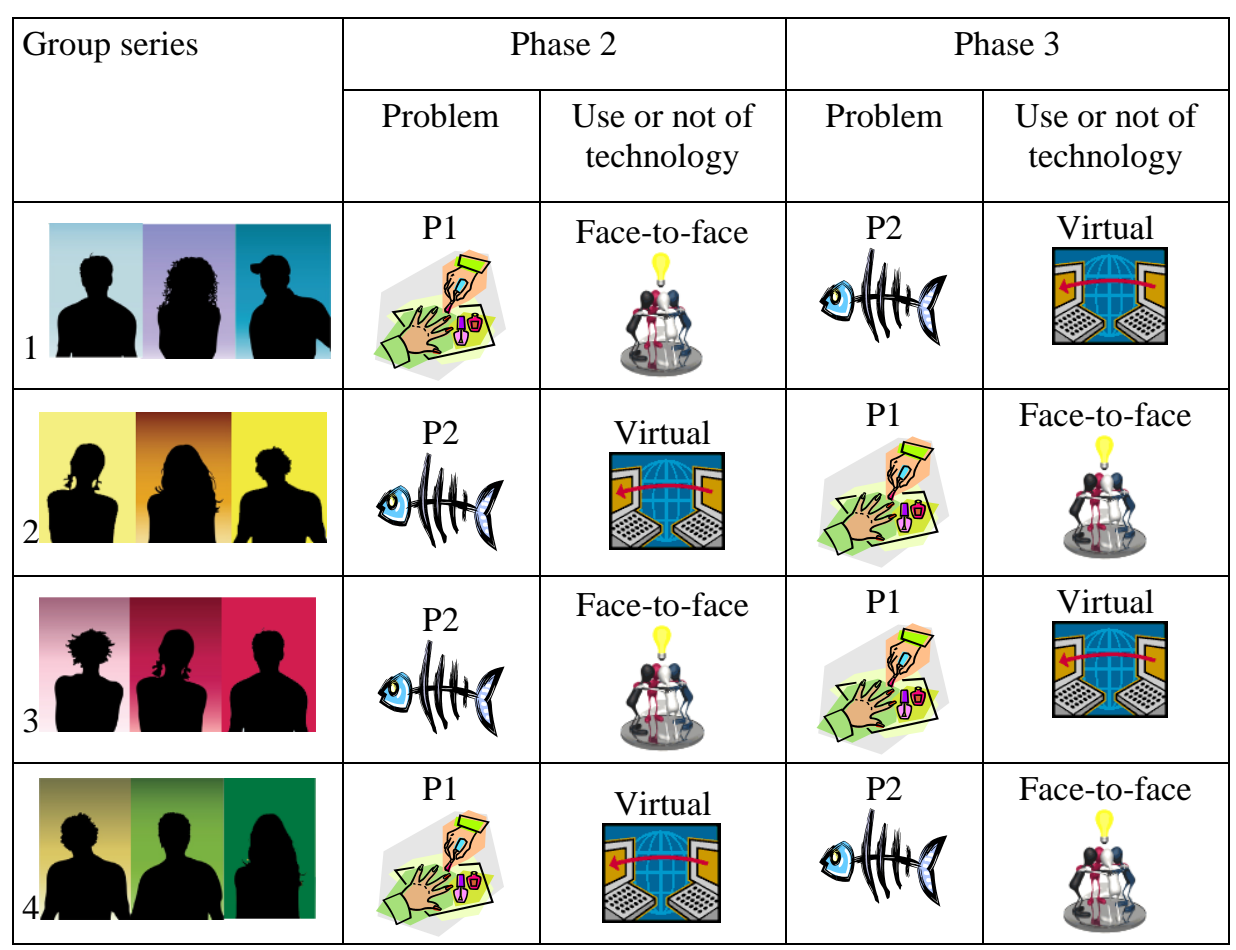

Phase 3 (50 minutes): problem solving 2

When phase 2 ends, the students that had been working face-to-face were separated and led to the isolated cubicles to work virtually and those teams that had been working in virtual teams in the previous phase were put together to work face-to-face. They followed the same schedule as in phase 2 , and they were asked to solve a different problem, as also shown in Table 2. So, for example, the team who worked faceto-face in order to solve problem P1in the previous phase is now working virtually to solve problem P2. The reason for alternating the beginning of each phase with or without ICT and with the problem (P1 and P2) is to eliminate the interferences caused by the order of the problem solving. The possible combinations of problems, phases and groups can be seen in Table 3, together with the codification model for each experiment output.

A code is assigned to each run of the experiment, which is in turn composed of three different codes separated by dashes. The first code corresponds to the number assigned to the group. So, G1 is the first group, G2 is the second one, etc. The second code is defined by the letters ST and CT, which indicates whether the outcome comes from a face-to-face group (ST for the abbreviation of "without ICT" in Spanish) or from virtual teams (CT for the abbreviation of "with ICT" in Spanish), which are followed by a number that indicates the order in which the experience was performed by the team. So, for example, the code ST1 will mean that this design corresponds to a face-to-face work, and this experiment was performed first (in phase 2). The third code corresponds to the problem solved by the group. 


\section{EXPERIMENTAL PHASE ORGANIZATION}

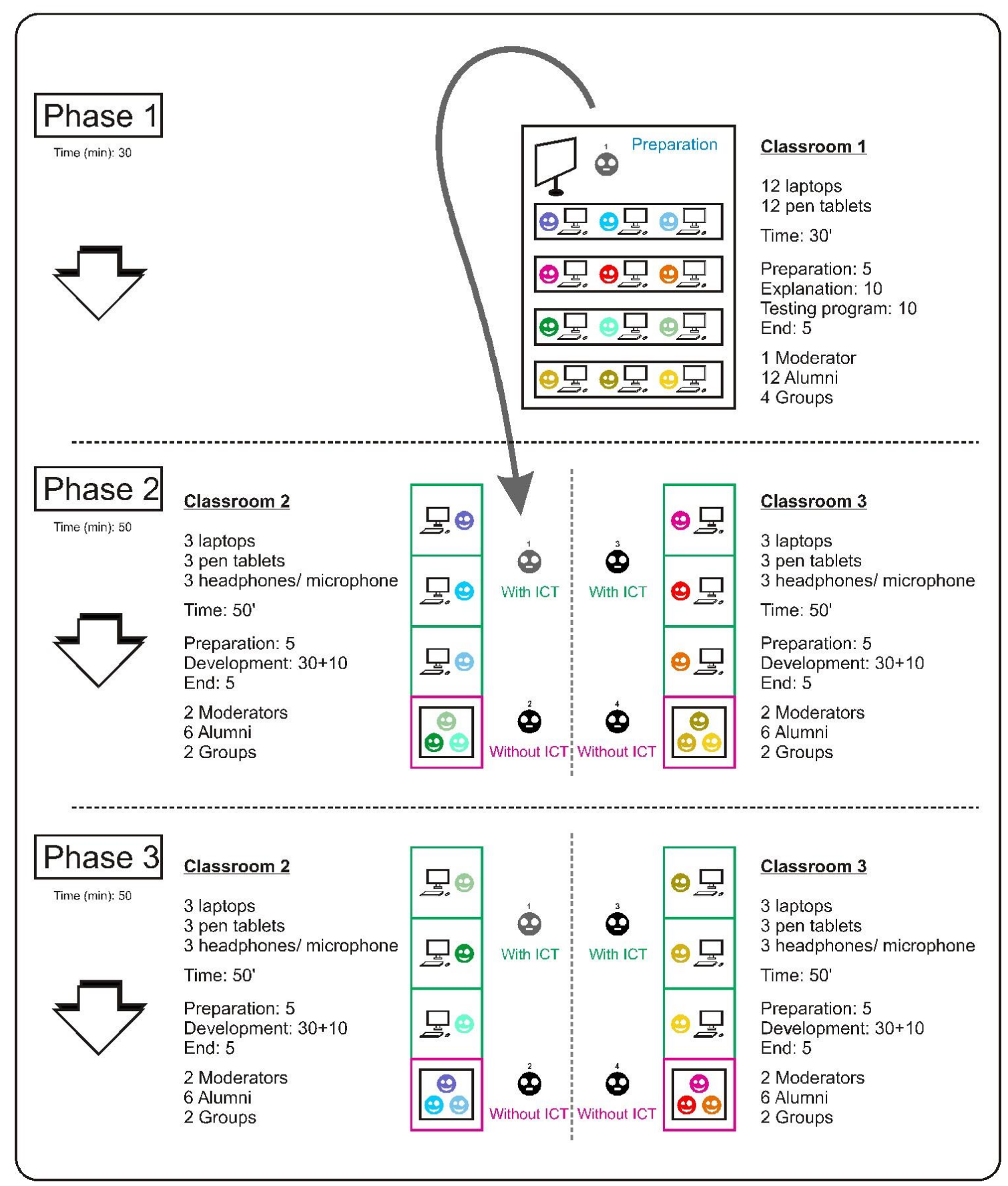

Figure 3: Students' distribution and phases of the experiment 
Table 3: Combinations and codification of the experiments

\begin{tabular}{|l|l|}
\hline $\begin{array}{l}\text { First problem 1 without ICT and later } \\
\text { problem 2 with ICT }\end{array}$ & $\begin{array}{l}\text { First problem 2 without ICT and later } \\
\text { problem 1 with ICT }\end{array}$ \\
\hline $\begin{array}{l}\text { G1-ST1-P1 and G1-CT2-P2 } \\
\text { G5-ST1-P1 and G5-CT2-P2 } \\
\text { G9-ST1-P1 and G9-CT2-P2 } \\
\ldots\end{array}$ & $\begin{array}{l}\text { G3-ST1-P2 and G3-CT2-P1 } \\
\text { G11-ST1-P2 and G11-CT2-P1 } \\
\cdots\end{array}$ \\
\hline $\begin{array}{l}\text { First problem 1 with ICT and later } \\
\text { problem 2 without ICT }\end{array}$ & $\begin{array}{l}\text { First problem 2 with ICT and later } \\
\text { problem 1 without ICT }\end{array}$ \\
\hline $\begin{array}{l}\text { G4-CT1-P1 and G4-ST2-P2 } \\
\text { G8-CT1-P1 and G8-ST2-P2 } \\
\text { G12-CT1-P1 and G12-ST2-P2 } \\
\ldots\end{array}$ & $\begin{array}{l}\text { G2-CT1-P2 and G2-ST2-P1 } \\
\text { G10-CT1-P2 and G10-ST2-P1 } \\
\cdots\end{array}$ \\
\hline
\end{tabular}

\subsection{Analysis tools}

The creativity of the outcomes was evaluated using the metric of Moss (Moss 1966). J. Moss elaborated a method of identification and estimation of the creativity level a product by combining two different parameters: usefulness and unusualness. According to Moss, the variable usefulness is determined by comparing the level of accomplishment of the product requirements with respect to a standard solution considered as satisfactory, which is called the "teacher's solution". This parameter is evaluated within a range of 0 to 3, where 0 means that the design fails to reach the minimum requirements, and a value of 3 corresponds to a solution that is better than the "teacher's solution". If the solution fulfils just the basic requirements but in a vague or imprecise way, its punctuation is 1 , while the value of 2 means that the solution has achieved the same functional quality as the "teacher's solution". Despite the fact that Moss' metric considers that only one evaluator is needed, in the present research it was preferred to make the assessment by the agreement of three experts in the field of Design Engineering, in order to avoid subjectivity. So, the three experts deliberated together about the value of unusualness, usefulness and creativity, and one value for each parameter was provided for statistical analysis. The same three experts determine together at the beginning of the evaluation phase which the "teacher's solution" will be.

The unusualness variable is determined by the inverse probability that this same concept appears within a homogenous group of solutions. Thus, the product must be compared with the rest of the products elaborated within a group of solutions for the same problem. This is a comparative method and, therefore, the evaluator must be familiar with the possible solutions that could appear and with which frequency they could do so. He or she must also be capable of deducing which level of probability of appearance is considered normal for average products, and of turning the deviations of probability into unusualness ratios. A value between 0 and 3 is also assigned to these ratios. Here, a value of 0 means that this is a common solution and a value of 3 corresponds to an exceptionally original idea. Lastly, the level of creativity of the final product is obtained by multiplying those two variables, being the final score between a minimum value of 0 and a maximum value of 9 , calculated as Creativity $=$ Usefulness $\mathrm{x}$ Unusualness (Table 4). 
3. Table 4: Moss scale (Moss, 1966)

\begin{tabular}{|l|l|l|l|l|l|}
\hline & & $\begin{array}{l}\text { The solution } \\
\text { does not satisfy } \\
\text { the functional } \\
\text { demands }\end{array}$ & $\begin{array}{l}\text { The solution } \\
\text { satisfies the } \\
\text { functional } \\
\text { demands in a } \\
\text { basic way }\end{array}$ & $\begin{array}{l}\text { The solution is as } \\
\text { good as the } \\
\text { standard }\end{array}$ & $\begin{array}{l}\text { The solution is } \\
\text { better than the } \\
\text { standard }\end{array}$ \\
\hline & & 0 & 1 & 2 & 3 \\
\hline$>10 \%$ of similar ideas & 0 & 0 & 0 & 0 & 0 \\
\hline $6-10 \%$ of similar ideas & 1 & 0 & 1 & 2 & 3 \\
\hline $1-5 \%$ of similar ideas & 2 & 0 & 2 & 4 & 9 \\
\hline$<1 \%$ of similar ideas & 3 & 0 & 3 & 6 & 6 \\
\hline
\end{tabular}

\section{Results}

Forty-two conceptual designs were obtained as a result of the experiment. Twenty-one of them involved a home device for painting fingernails (Figures 4 and 5) and the other 21 corresponded to a domestic device for extracting the fishbone from small and medium-sized fish (Figures 6 and 7). Handmade designs by the physical working groups were digitized in the same format as those produced using ICT tools to avoid conditioning the evaluators. 


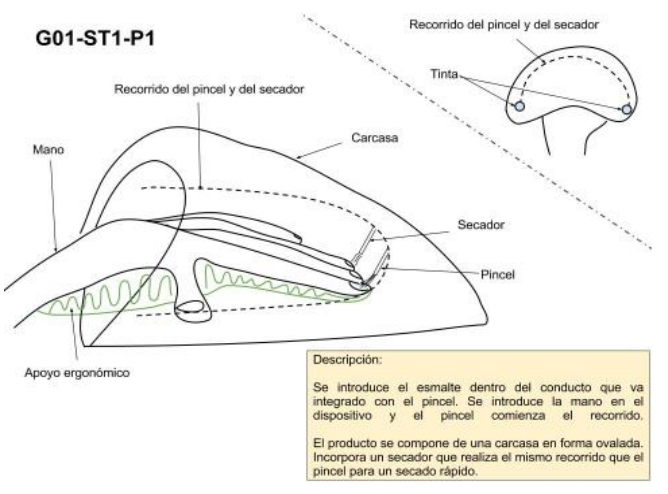

G03-ST1-P1

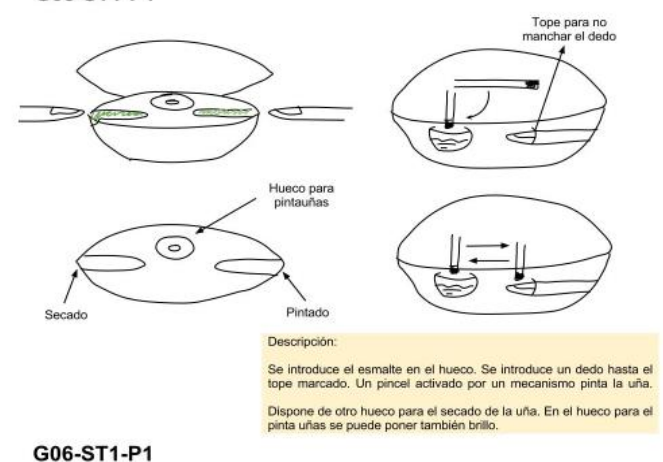

G06-ST1-P1
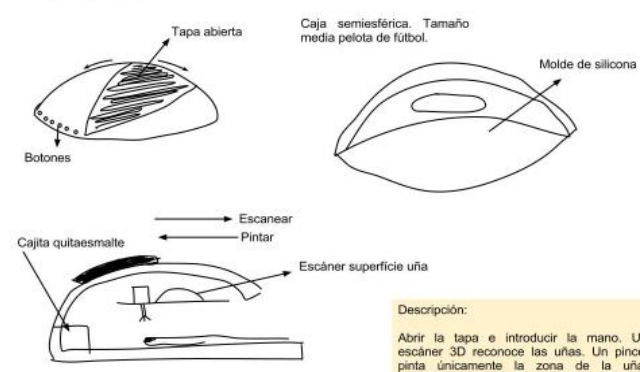

Descripio

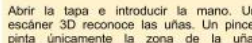

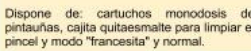

G12-ST2-P1

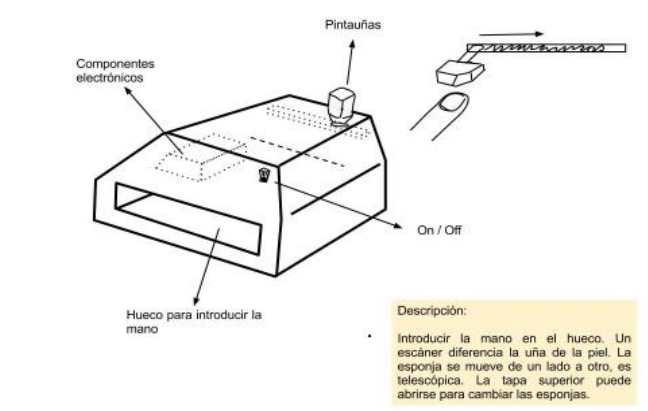

G16-ST1-P1
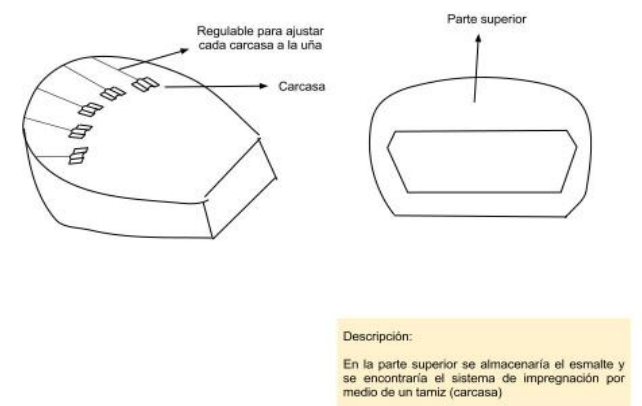

G02-ST2-P1

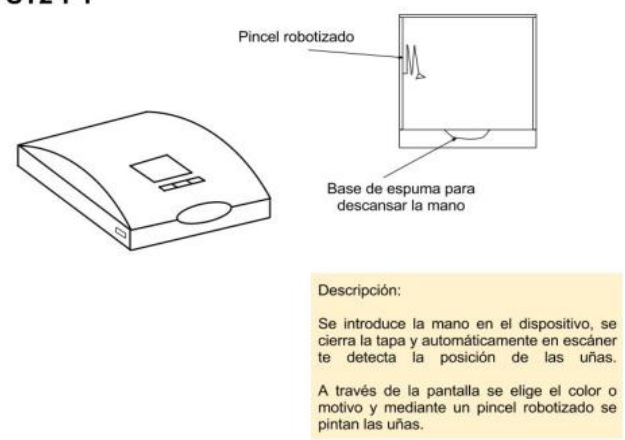

G05-ST1-P1

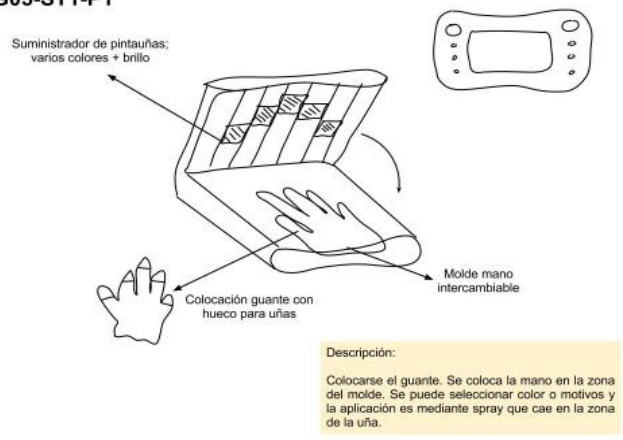

G10-ST2-P1

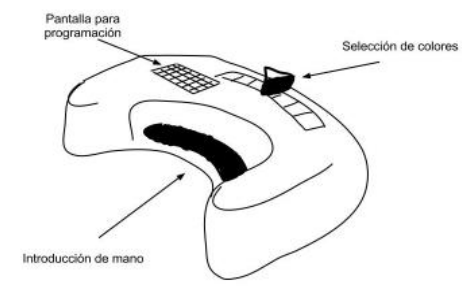

Descripción:

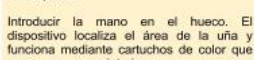

G13-ST1-P1
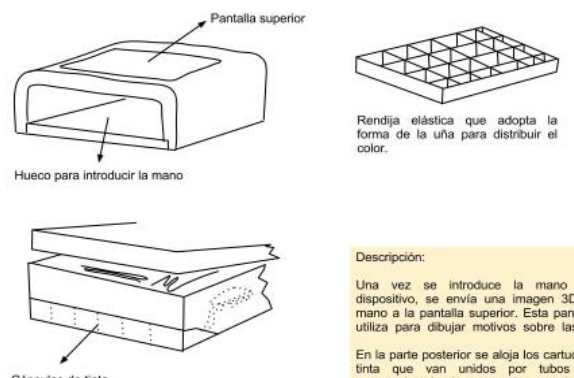

Descripcion:

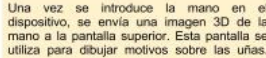

En la parte posterior se aloja los cartuchos de
tinta que van unidos por tubos a un

G19-ST2-P1
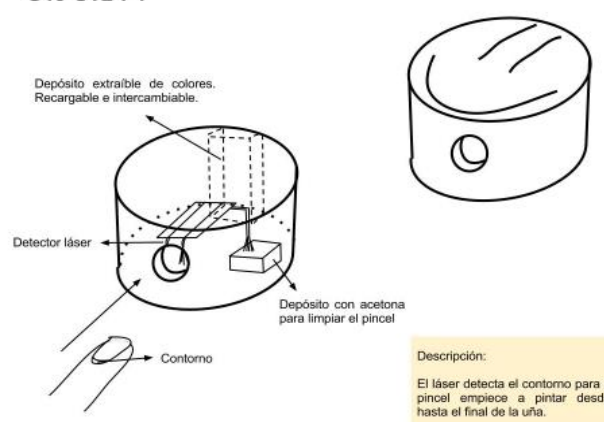

Descripción.

El laser detecta el contomo para que el
pincole empioco a pintar desde ahi

Figure 4. Conceptual designs for a home device for painting fingernails, with no ICTs 
G04-CT1-P1
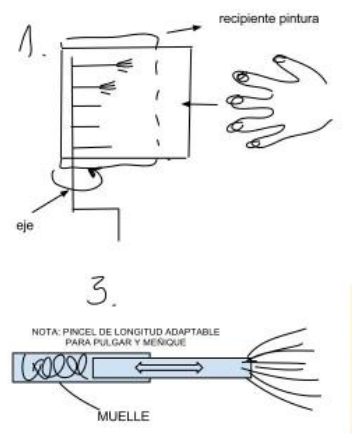

Descripcion:

Ponerse el guante con huecos para la zona de
las unas y posicionar la mano en el dispositivo.

E dispositivo consta de cinos pinceles
enganchados a un eje of girio. Se les haco pasar

G08-CT1-P1

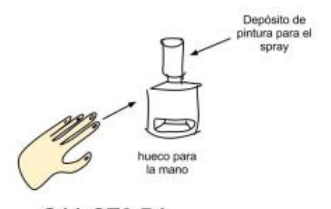

G11-CT2-P1

Descripoion:

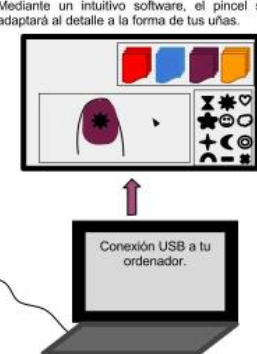

El dispositivo está preparado para reconocer formas de unâs.
Se introduce la forma de la uña, se elige un diseño y los colores. La intormación pasará de un ordenador al dispositiving

G15-CT1-P1

pantala para elegir
el diseño de uñas

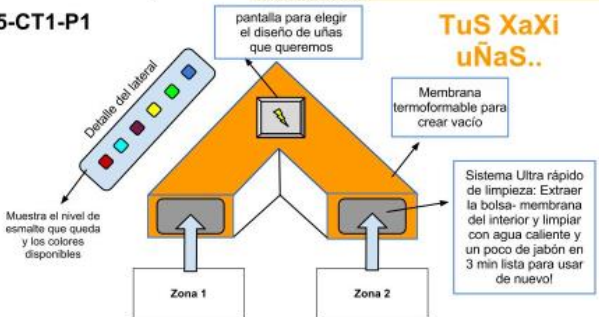

Descripción:

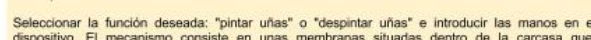

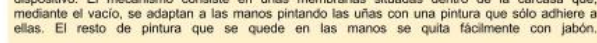

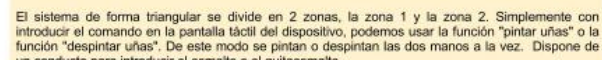

G18-CT1-P1

G20-CT2-P1 por un deposito de pintura inferior (ver figura 2).
A seguir girando ef eje los pinceles contactan

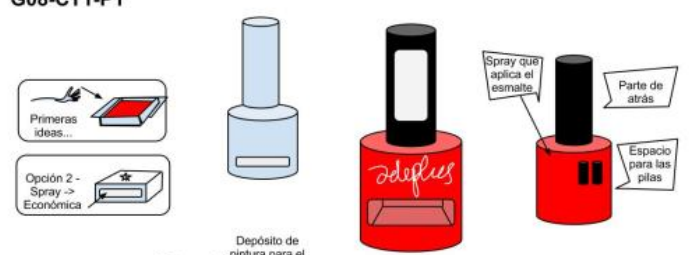

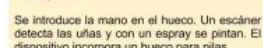

G07-CT1-P1

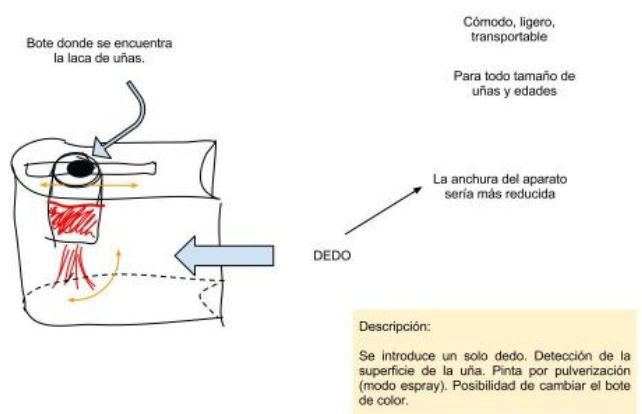

G09-CT2-P1
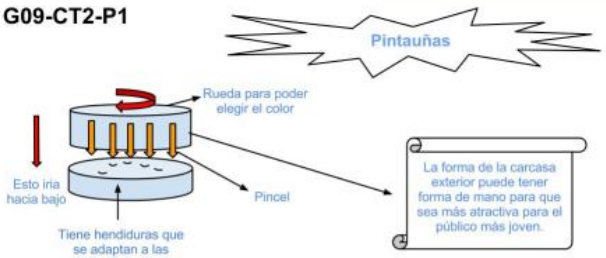

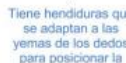

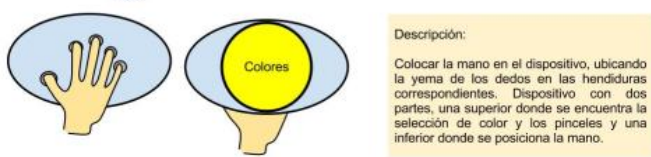

G14-CT1-P1

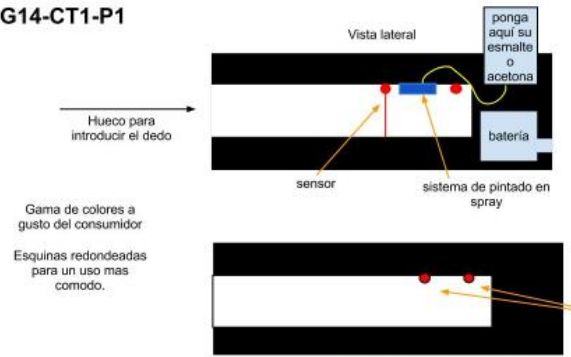

Descripción:

Se introduce un dedo en el dispositivo. Los sensores una y alustan el spray. Existe una entrada para poner
bote de esmalte o de acetona para el autolimpiado de

G17-CT2-P1

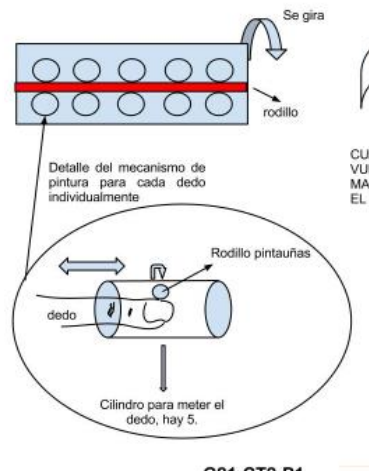

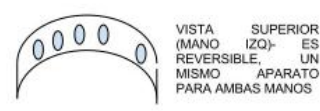

CUANDO LE DAMOS LA
VUELTA PARA LA
MANO IZO USAREMOS
EL HUECO 2 2

Descripción:

Se introduce cada dedo en su agujero
correspondiente (los de una mano). Cuando

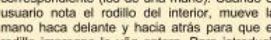
mano haca delante y hacia atras para que el
rodillio impregne ta unua entera. Para introducir
los dodos de la otra mano es necesario darle la
vuetla al dispositivo.

G21-CT2-P1

PINTAFACIL

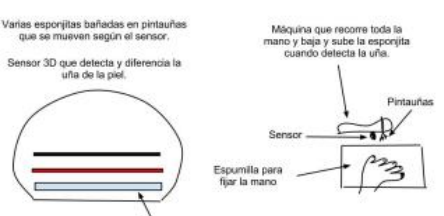

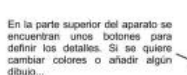
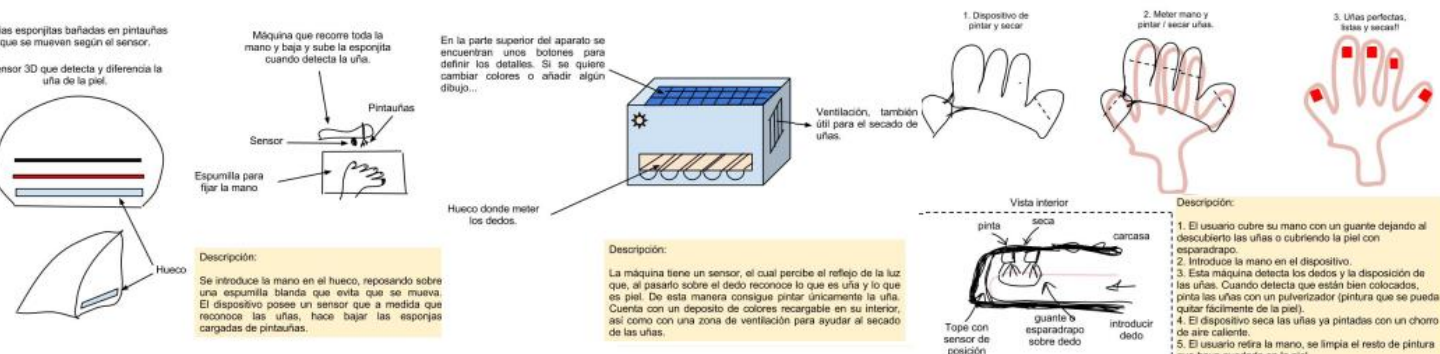

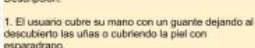

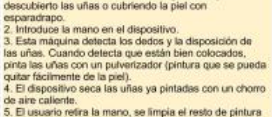

Figure 5. Conceptual designs for a home device for painting fingernails, with ICTs 

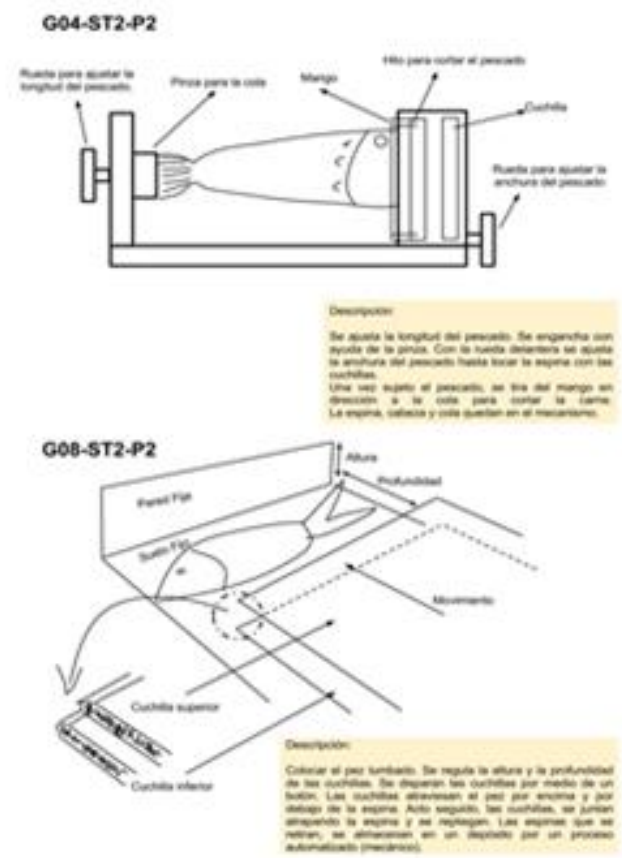

G11-\$T1-P2

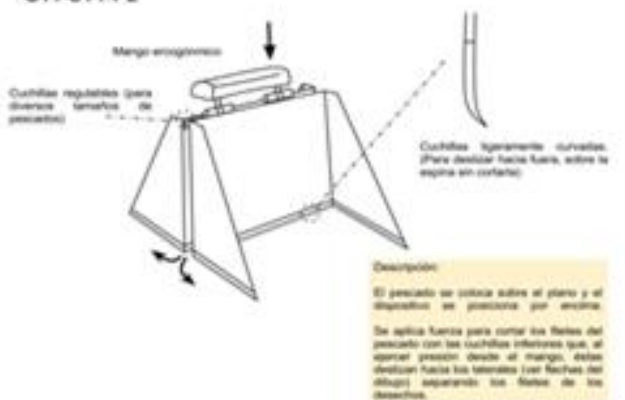

G15-\$T2-P2

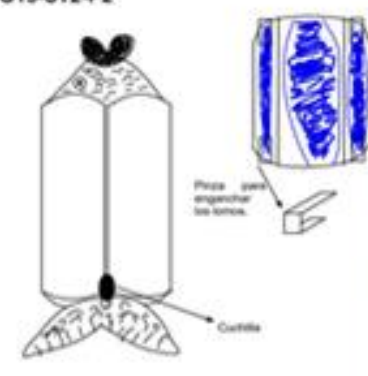

618-smen

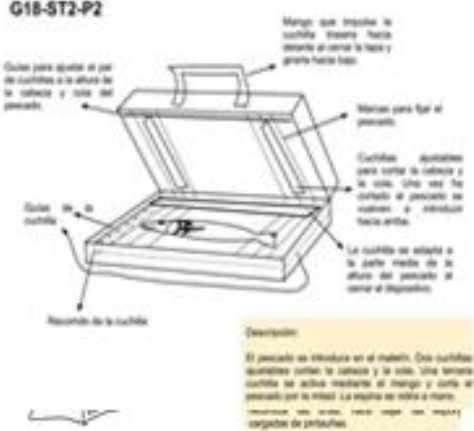

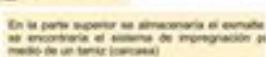

casting
G07-sT2-P2

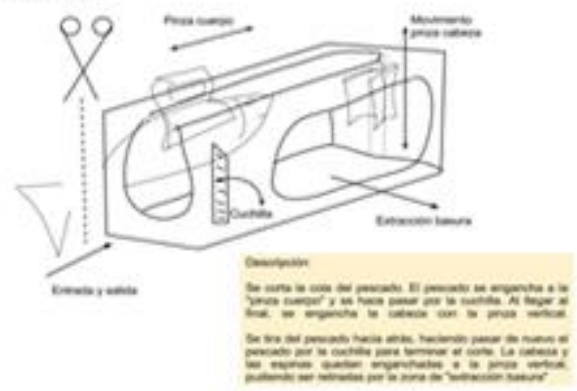

cos-st1.p2

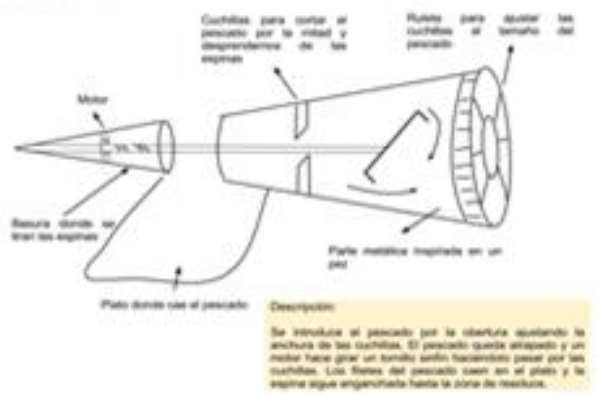

G14-5T2-P2

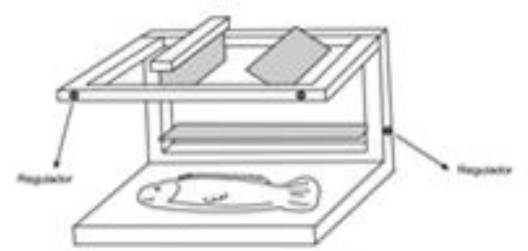

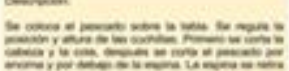

G17-ST1-P2
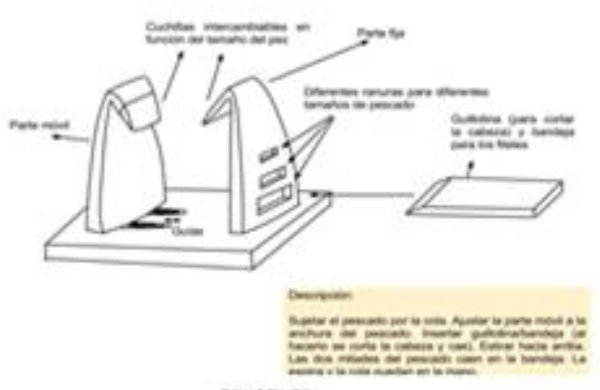

c21-5T12
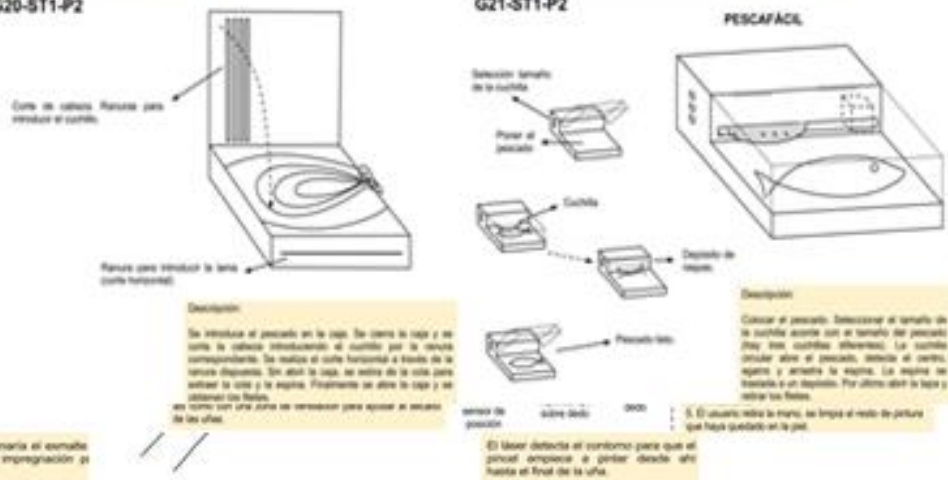

Figure 6. Conceptual designs for a home device for extracting the fishbone, with no ICTs 
G01-CT2-P2
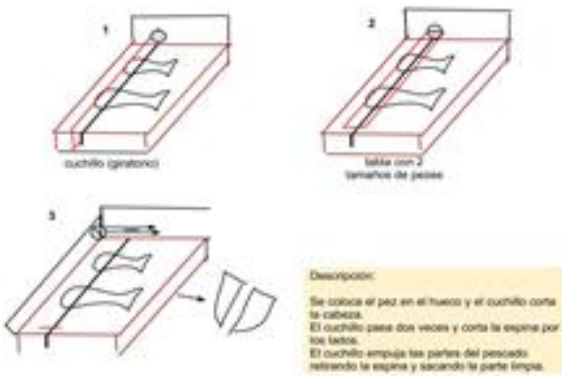

G03.CT2.P2
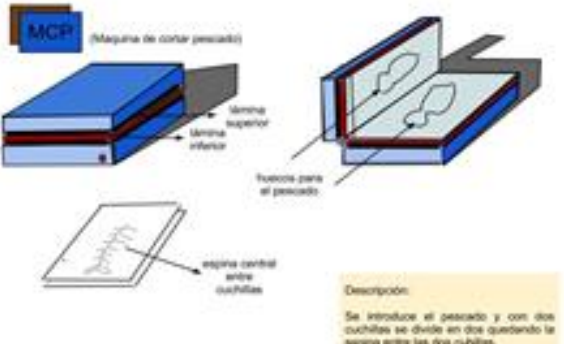

G06-CT2-P2
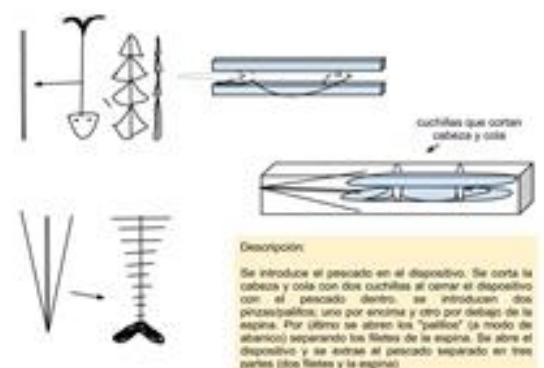

G13-CT2-P2

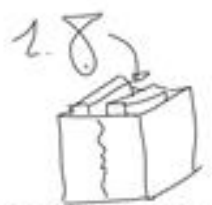

2.
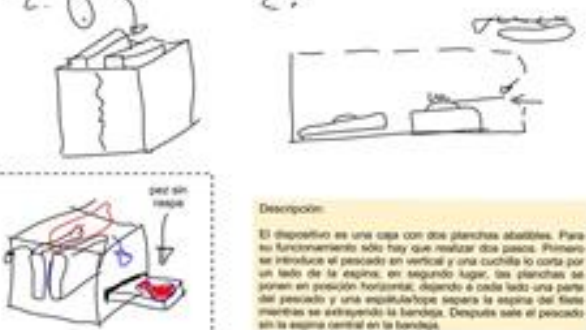

G16.CT2-P2
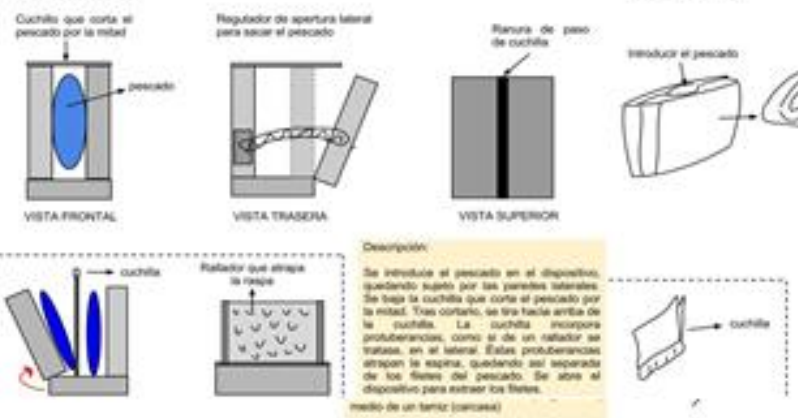

G02-CT1-P2
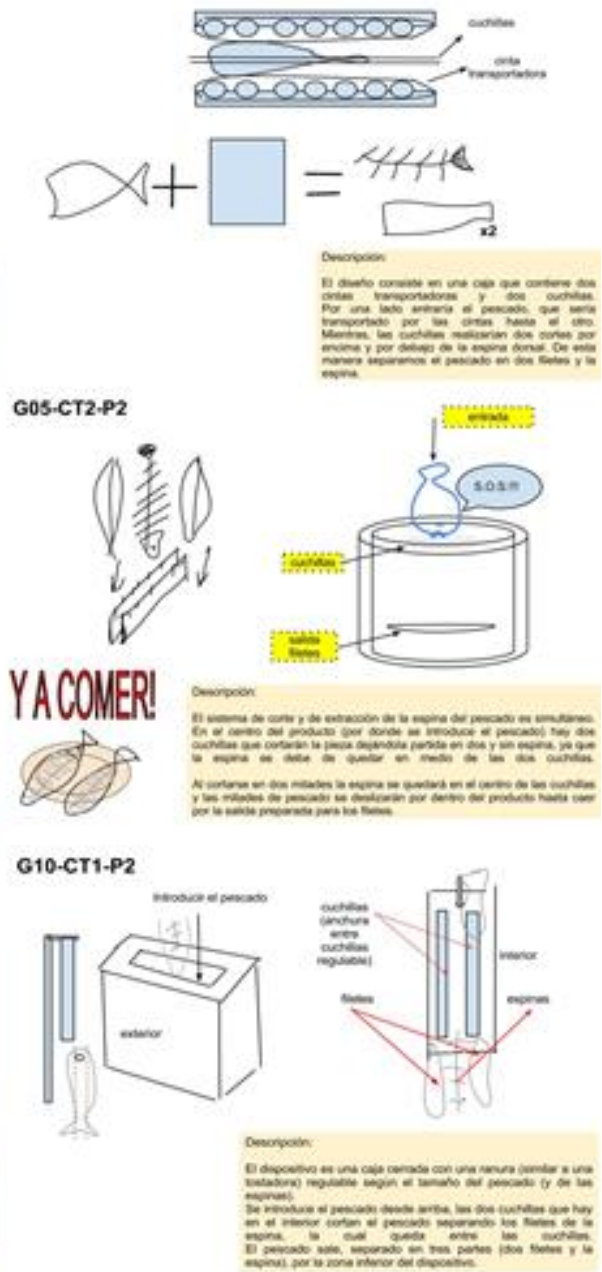

G12-CT1-P2

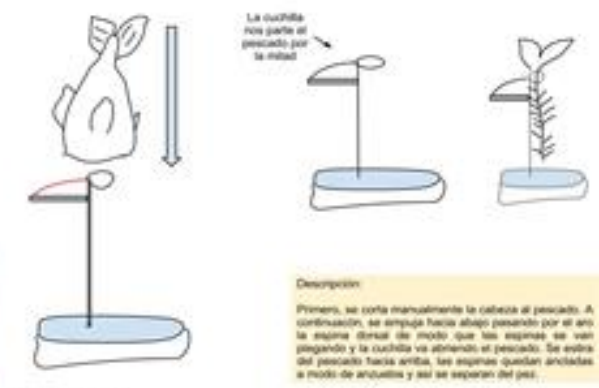

G19-CT1.P2

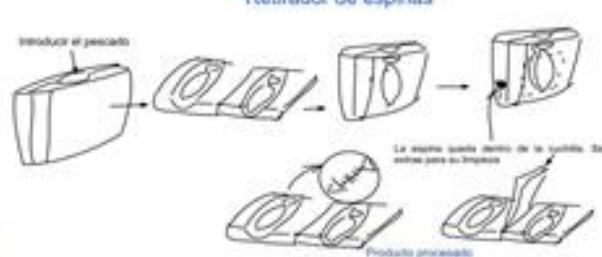

Figure 7. Conceptual designs for a home device for extracting the fishbone, with ICTs 
Using the metric of Moss (1966), three experts in the field of Design Engineering evaluated together, by consensus, parameters such as unusualness, usefulness and creativity for each of the 42 designs submitted. According to this assessment method, unusualness is evaluated by comparing the conceptual designs provided but, in order to be able to perform the usefulness evaluation, first the "teacher's solution" must be defined. The assessment criteria that the evaluators together concluded by agreement for both problems are, in functional terms, as follows:

Home device for painting fingernails:

- The device must paint the nails and only the nails. At the end of the process, fingers must be clean. A mechanical system of blocks to limit the nail is proposed.

- The device must have several deposits for different colours, and it must have a selection system to choose which single colour is desired (such as buttons).

- Nails will be painted using a brush.

- $\quad$ The device will run automatically, so electrical energy is needed.

Home device to extract the fishbone:

- $\quad$ The device must remove the fishbone, the tail and the head of the fish.

- This action will be performed using between one and three solid blades.

- The fishbone will be removed by one or two hooks.

- $\quad$ The device will run automatically, so electrical energy is needed.

Accordingly, Table 5 shows some examples of evaluation of the problems.

Table 5. Examples of evaluation of the problems

\begin{tabular}{|l|l|}
\hline G01-ST1-P1 & $\begin{array}{l}\text { Usefulness = 1. The device accomplishes the basic function of painting the nails, but it } \\
\text { has no deposits to store colours. It also has no system to ensure that the fingers will not } \\
\text { get painted. } \\
\text { Unusualness }=0 . \text { The concept is similar to several of the other solutions submitted. } \\
\text { Creativity }=1 \times 0=0\end{array}$ \\
\hline G02-ST2-P1 & $\begin{array}{l}\text { Usefulness }=3 . \text { The device accomplishes all the functions proposed in the "teacher's } \\
\text { solution", and it also presents several improvements like a scanner for nail detection, } \\
\text { robotic arm, ergonomic handrest or USB connection for selecting designs. } \\
\text { Unusualness }=3 . \text { The concept is not similar to the others, and all the evaluators coincide } \\
\text { on the originality of the idea. } \\
\text { Creativity }=3 \times 3=9\end{array}$ \\
\hline $\begin{array}{l}\text { G05-CT2- } \\
\text { P2 }\end{array}$ & $\begin{array}{l}\text { Usefulness }=0 . \text { The opinion of all the evaluators is that dropping the fish onto the blades } \\
\text { will not ensure that it is going to be cut into the three parts shown in the drawing. This } \\
\text { could only be accomplished if the fish is dropped well on target and does not bend. } \\
\text { Moreover, the thickness of the blade would probably not separate the head from the } \\
\text { body, but just split it with the rest of the fish. } \\
\text { Unusualness = 0. The concept of dropping the fish onto blades has been presented by }\end{array}$ \\
\hline
\end{tabular}




\begin{tabular}{|l|l|}
\hline & $\begin{array}{l}\text { several teams. } \\
\text { Creativity }=0 \times 0=0\end{array}$ \\
\hline G21-ST1-P2 & $\begin{array}{l}\text { Usefulness }=2 . \text { The device performs all the functions proposed in the "teacher's } \\
\text { solution" (automated fish opening and fishbone extraction) and the evaluators agree that } \\
\text { those functions would achieve the same level of quality. } \\
\text { Unusualness }=2 . \text { The concept is not exact but close to another proposed solution. } \\
\text { Creativity }=2 \times 2=4\end{array}$ \\
\hline
\end{tabular}

The results of the evaluation of all the outcomes are shown in Table 6. It can be seen that many of the solutions have a very low score on creativity, either because the solution does not meet the demands or does so in a very basic way (utility 0 or 1 ) or because there are at least $6 \%-10 \%$ of similar ideas (Unusualness 0 or 1), or due to both reasons simultaneously.

Table 6. Results of measures of unusualness, usefulness and creativity

\begin{tabular}{|r|c|c|c|c|c|c|c|c|}
\hline & \multicolumn{9}{|c|}{ ST } & \multicolumn{4}{c|}{ CT } \\
\hline Group & Problem & Usefulness & Unusualness & Creativity & Problem & Unusualness & Unusualness & Creativity \\
\hline 1 & 1 & 1 & 0 & 0 & 2 & 1 & 1 & 1 \\
\hline 2 & 1 & 3 & 3 & 9 & 2 & 1 & 2 & 2 \\
\hline 3 & 1 & 1 & 0 & 0 & 2 & 1 & 0 & 0 \\
\hline 5 & 1 & 2 & 2 & 4 & 2 & 0 & 0 & 0 \\
\hline 6 & 1 & 3 & 0 & 0 & 2 & 1 & 2 & 2 \\
\hline 10 & 1 & 3 & 0 & 0 & 2 & 0 & 0 & 0 \\
\hline 12 & 1 & 2 & 0 & 0 & 2 & 1 & 2 & 2 \\
\hline 13 & 1 & 3 & 3 & 9 & 2 & 0 & 0 & 0 \\
\hline 16 & 1 & 0 & 0 & 0 & 2 & 2 & 2 & 4 \\
\hline 19 & 1 & 1 & 0 & 0 & 2 & 1 & 0 & 0 \\
\hline 4 & 2 & 2 & 1 & 2 & 1 & 0 & 2 & 0 \\
\hline 7 & 2 & 0 & 1 & 0 & 1 & 1 & 0 & 0 \\
\hline 8 & 2 & 1 & 0 & 0 & 1 & 1 & 0 & 0 \\
\hline 9 & 2 & 0 & 2 & 0 & 1 & 0 & 0 & 0 \\
\hline 11 & 2 & 0 & 2 & 0 & 1 & 2 & 0 & 0 \\
\hline 14 & 2 & 0 & 0 & 0 & 1 & 2 & 0 & 0 \\
\hline 15 & 2 & 2 & 3 & 6 & 1 & 3 & 3 & 9 \\
\hline 17 & 2 & 2 & 1 & 2 & 1 & 1 & 0 & 0 \\
\hline 18 & 2 & 1 & 0 & 0 & 1 & 1 & 0 & 0 \\
\hline 20 & 2 & 2 & 0 & 0 & 1 & 2 & 1 & 2 \\
\hline 21 & 2 & 2 & 2 & 4 & 1 & 2 & 1 & 2 \\
\hline
\end{tabular}

Figure 8 shows the box plots of the degree of usefulness, unusualness and creativity in order to better visualize the similarities between the two ways of working. The graph shows that the degree of unusualness and creativity is distributed in the same way when working with or without technology, in all cases averages with a value of 0 being obtained, which means that half of the results have that value. In the degree of usefulness, however, differences are observed between using or not using technologies, as the average score when using technologies is 1 , while its value is 2 when they are not used. 


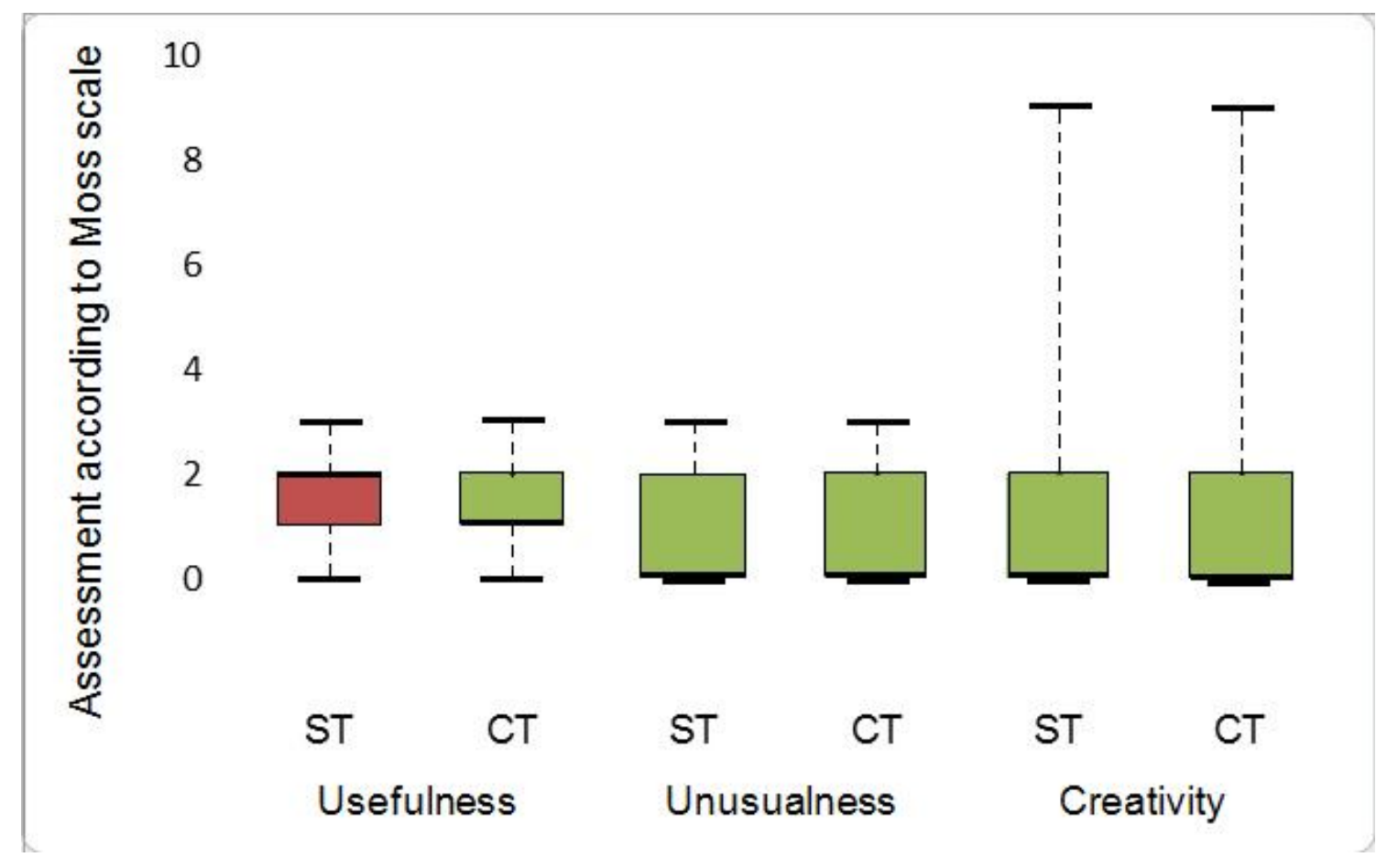

Figure 8. Rating the degree of usefulness, unusualness and creativity using the scale of Moss

Table 7 shows the number of times that the solutions of the same design team had been rated better when working without technologies and the number of times that their solutions had been rated better when they worked with technologies. This value is indicated as a total and separately for each of the two problems (P1 and P2). As can be observed, there is no clear trend showing an influence of the work environment on the degree of creativity of the results, as there are groups that produce better-rated results when working with technologies and groups in which this happens when working without technologies. Of the 21 groups, there are 7 that obtain the same ratings in both cases, whereas in the degree of unusualness 8 groups are better with technologies and 6 are better without technologies, something similar also happening with the other two parameters. This allows us to deduce that the possible influence of the working environment on the ratings of the designed solutions is not consistent.

Table 7. Number of times that the design team is rated best in each work environment: with ICTs (CT) or without ITCs (ST)

\begin{tabular}{|l|c|c|c|c|c|c|}
\cline { 2 - 7 } \multicolumn{1}{c|}{} & \multicolumn{2}{c|}{ Usefulness } & \multicolumn{2}{c|}{ Unusualness } & \multicolumn{2}{c|}{ Creativity } \\
\hline & CT & ST & CT & ST & CT & ST \\
\hline Total & 8 & 5 & 8 & 6 & 6 & 6 \\
\hline P1 & 6 & 4 & 3 & 2 & 3 & 2 \\
\hline P2 & 2 & 1 & 5 & 4 & 3 & 4 \\
\hline
\end{tabular}

Table 8 shows the values of usefulness, unusualness and creativity of the proposals according to the problem, according to the working mode (physically or virtually), and combining both parameters. This table shows that problem 1 (P1) seems to give better results in terms of usefulness and creativity, while problem 2 (P2) seems to work better in unusualness. Similarly, the averages of the three parameters are higher when working in physical teams. With the aim of verifying whether these differences are 
significant, the data were analysed statistically.

Table 8. Average ratings for parameters of usefulness, unusualness and creativity

\begin{tabular}{|l|c|c|c|c|c|c|c|c|c|}
\cline { 2 - 10 } \multicolumn{1}{c|}{} & \multicolumn{3}{c|}{ Usefulness } & \multicolumn{3}{c|}{ Unusualness } & \multicolumn{3}{c|}{ Creativity } \\
\cline { 2 - 10 } \multicolumn{1}{c|}{} & CT & ST & Total & CT & ST & Total & CT & ST & Total \\
\hline P1 & 1.36 & 1.90 & 1.62 & 0.64 & 0.80 & 0.71 & 1.18 & 2.20 & 1.67 \\
\hline P2 & 0.80 & 1.09 & 0.95 & 0.90 & 1.09 & 1.00 & 1.10 & 1.27 & 1.19 \\
\hline Total & 1.08 & 1.50 & 1.29 & 0.77 & 0.95 & 0.86 & 1.14 & 1.74 & 1.43 \\
\hline
\end{tabular}

The average values in Table 8 show that the degrees of usefulness, unusualness and creativity are slightly higher when working face-to-face, but, as seen in Table 7, there are groups that get better ratings when working face-to-face, while in other design groups the opposite occurs. On analysing the degree of utility and unusualness it can be seen that the ratings are slightly higher for groups without ICTs. Regarding the degree of usefulness, the differences between using and not using technologies are slightly higher than in the unusualness parameter. From the box plot graph it can be deduced that the data do not follow a normal distribution, which has also been checked with a Shapiro-Wilks test. So, the median of the two samples have to be compared. In this analysis the data are paired, this is, the design groups of the two samples (sample with problem 1 and sample with problem 2 and sample with ICT and without them) are the same. Then to test whether differences in the median value are statistically significant, a Wilcoxon test was performed with the data obtained. The Wilcoxon test of our set of samples consisted in testing the null hypothesis ("the median of the result of solving any of the problems described is the same" and "the median of the result of using ICT or not to solve the problems is the same") against the alternative hypothesis ("the median of the result of solving any of the problems described is different" and "the median of the result of using ICT or not to solve the problems is different") with an $\alpha$ error $=0.05$. In this test, the differences of the subjects in the two samples are calculated and ranked to obtain a statistic called "T" which is compared against the lower and upper critical values (W) of Wilcoxon Signed Ranks Test. In addition, it has been considered that the statistic $\mathrm{T}$ follows a normal distribution and the value $\mathrm{z}$ is obtained from the experimental value of $\mathrm{T}$ and tested against a standard normal distribution (critical value 1,96 for a $\alpha=0.05$ ) Thus:

- If T $€$ [Tcritlow, Tcritup], the null hypothesis is accepted (the problem/use of ICT has no effect).

- If $\mathrm{T}$ does not belong to the interval of the lower and upper critical values, the null hypothesis is rejected.

- If $Z>$ criticalZ, the null hypothesis is rejected (i.e. the problem/use of ICT has an effect).

- If $Z \leq$ criticalZ, the null hypothesis is accepted (i.e. the problem/use of ICT has no effect).

The first statistical analysis was performed to check whether the problem has influenced the results of unusualness, usefulness and creativity. The Wilcoxon analysis results are shown in Table 9, where it is possible to see how the problem has not affected the results although the usefulness is in the limit.

Table 9. Influence of the kind of problem on the level of unusualness, utility and creativity for $\alpha=$ 


\begin{tabular}{|l|r|r|}
\hline Parameter & \multicolumn{1}{|c|}{$\mathrm{T}$, Tcritical interval } & \multicolumn{1}{|l|}{$\mathrm{Z}$-critical $=1.96 ;-1.96$} \\
\hline Unusualness & $36.5 €(21,84) \mathrm{n}=14$ & $\mathrm{Z}=-1,0280.74, \mathrm{p}=0.304$ \\
\hline Usefulness & $18.5 €(17,74) \mathrm{n}=13$ & $\mathrm{Z}=-1.927, \mathrm{p}=0.054$ \\
\hline Creativity & $33 €(13,65) \mathrm{n}=12$ & $\mathrm{Z}=-0.477, \mathrm{p}=0.633$ \\
\hline
\end{tabular}

On the other hand, we also analysed the influence that the use of ICTs, or not, had on the results of unusualness, usefulness and creativity. Table 10 shows the results of statistical analyses performed for this purpose. As we can see, the data suggest that the fact of working in person or virtually did not influence the levels of unusualness, usefulness or creativity of the results.

Table 10. Influence of using ICT, or not, on the level of unusualness, usefulness and creativity for $\alpha=0.05$

\begin{tabular}{|l|r|r|}
\hline Parameter & T, Tcritical interval & \multicolumn{1}{|c|}{ F-critical $=1.96$} \\
\hline Unusualness & $43.5 €(21.84) \mathrm{n}=14$ & $\mathrm{Z}=-0.578 \mathrm{p}=0.5639$ \\
\hline Usefulness & $29 €(17.74) \mathrm{n}=13$ & $\mathrm{Z}=-1.177 \mathrm{p}=0.239$ \\
\hline Creativity & $32 €(13.65) \mathrm{n}=12$ & $\mathrm{Z}=-0.557 \mathrm{p}=0.578$ \\
\hline
\end{tabular}

However, since the first analysis showed that the usefulness was very near the critical value when the differences against the design problem have been analysed, we decided to check whether in-person or distance work, using ICT tools or not, has any influence on the unusualness, usefulness and creativity values of the solutions, the results being separated according to the problem solved. Since the samples are separated for each problem, now the data of each sample are independent (the design teams solving a specific problem (problem 1 for instance) using ICT are different to the design teams that did not use ICT. So, the non-parametric U de Mann-Whitney test has been applied in this case. The test results displayed in Table 11 show that in this case the use of ICT tools, or not, has hardly any influence.

Table 11. Influence of using ICT, or not, on the level of unusualness, usefulness and creativity, according to the proposed problem

\begin{tabular}{|l|l|r|}
\hline for $\alpha=0.05$ Problem & Parameter & Z-critical $=1.96$ \\
\hline \multirow{3}{*}{1} & Unusualness & $\mathrm{Z}=-0,547, \mathrm{p}=0,585$ \\
\cline { 2 - 3 } & Usefulness & $\mathrm{Z}=-0,512, \mathrm{p}=0,608$ \\
\cline { 2 - 3 } 2 & Creativity & $\mathrm{Z}=-0,88 \mathrm{p}=0,973$ \\
\hline \multirow{3}{*}{2} & Unusualness & $\mathrm{Z}-0,375, \mathrm{p}=0,707=$ \\
\cline { 2 - 3 } & Usefulness & $\mathrm{Z}=-0,224, \mathrm{p}=0,822$ \\
\cline { 2 - 3 } & Creativity & $\mathrm{Z}=-0,630, \mathrm{p}=0,529$ \\
\hline
\end{tabular}

Also, it has be seen that the problem seems to affect the results of usefulness of the designs, but a new analysis must be done in order to see if the problem order have any effect on the results. Again, a $U$ de Mann-Whitney test has been done providing with the results shown in Table 12. There it can be seen that the order in which the problem is solved has no significative effect in the unusualness, usefulness or creativity of the results.. 
Table 12. Influence of the order of problem solving, on the level of unusualness, usefulness and creativity for $\alpha=0.05$

\begin{tabular}{|l|r|l|}
\hline Parameter & \multicolumn{2}{|c|}{ Z-critical $=1.96$} \\
\hline Unusualness & Order & $\mathrm{Z}=-1.107, \mathrm{p}=0.268$ \\
& & \\
\hline Usefulness & Order & $\begin{array}{l}\mathrm{Z}=-0.093, \mathrm{p}=0.926 \mathrm{~F}(1,38)= \\
1.07, \mathrm{p}=0.307\end{array}$ \\
& & \\
\hline Creativity & Order & $\mathrm{Z}=-1.190, \mathrm{p}=0.234$ \\
& & \\
\hline
\end{tabular}

\section{Discussion}

The assessment of creativity in the concepts generated using the Moss scale shows that when the group works face-to-face, the degree of creativity is somewhat higher (1.74) than when working and communicating through technologies (1.14) (Table 8). These values are modest, since on the Moss scale creativity values range between 0 and 9 . If we examine the degree of utility and of unusualness separately the same thing happens: the results are slightly higher for groups that work without technology, but in both cases the values obtained are modest, their values ranging from 0 to 3 , and they are slightly lower, particularly in the degree of unusualness. In the degree of usefulness, the differences between using ICTs, or not, are a little more noticeable. Furthermore, the influence of using technologies or not is not consistent, as 6 of the 12 groups obtained higher scores on the degree of creativity when they worked face-to-face, while the other 6 groups scored better on creativity when they worked using technologies.

Wilcoxon analysis shows that the difference in the degree of creativity is no significant, and therefore it can be stated that the values of novelty, usefulness and creativity obtained are not affected by the use of ICTs in design teams. This means that these three values did not vary significantly depending on whether the groups worked in person or virtually. These findings suggest that both modes are equally effective, and thus the implementation of a virtual work mode is generally positive and does not affect the results negatively.

The fact that the degree of creativity is a little higher for face-to-face work may be because in the scenario in which the members of each group communicated through the computer, they could not communicate by voice or see each other, so this could somehow affect the ability of the group to generate ideas. In this regard, the fact of not being able to make eye contact eliminates the option of communicating ideas through gestures and nonverbal communication (Knapp and Hall 2009), which can be detrimental for group creativity. Indeed, there are studies that claim that the visual transmission of information acts as cognitive stimulation for creative processes (Rivera et al. 2010).

The results of this study are similar to those obtained in the study by Tang (Tang et al. 2011), in which 
third-year industrial design students working in pairs generated solutions to a creative problem, alternatively in a face-to-face situation and in a virtual environment that simulated face-to-face conditions. In Tang's study, the solutions were scored numerically by experts on seven criteria, including functionality and innovation, which would be more akin to the usefulness and unusualness criteria used in this study. Although in the traditional environment the scores were a little bit higher than in the digital one, statistics show that the setting employed to generate creative solutions to a new problem had no influence on the results.

Furthermore, the results obtained in this experiment may have been influenced by the fact that all participants are university students, that is, young designers who are very familiar with the use of these technologies. While it is true that the same experiment in a more adult population could vary in its results (Atman et al. 2005), we can predict that the profile of the designer who will work with virtual design tools in the future will be more like those who participated in this study, so that the results can be considered as valid.

On the other hand, the scores of the solutions vary depending on the design problem, being more creative and useful in the case of the nail polish device, although the unusualness score is somewhat higher in the fishbone extractor device Again, Wilcoxon analysis shows that there are no significant difference in the results depending on the design problem.

This result may be due to both the experience and motivation of the designers. In fact, the profile of the participants in the experiment indicates that they were young people and more than $60 \%$ were women. This means that at least $60 \%$ had previous experience in the nail painting process and the problems that resulted from it, while the fact that the participants' profile is defined by young students suggests that most of them probably still live with their parents, and have never or almost never faced the problem of removing a fishbone.

Informal conversations with students conducted at the end of the experiment confirm that motivation was different for the two problems, being lower for the problem related to filleting the fish. In this design problem it is worth noting that the scores between the groups that solved it using ICTs and those who solved it working in person are more similar (Table 8) than the scores obtained when they worked with the problem related to the nail polish device. However, the study does not supply sufficient data to determine whether the motivation from the problem may be a factor that exerts a significant influence on the creativity of the results.

Following this line, a deeper analysis of participant's opinion was carried out, whose conclusions can be seen in (Mulet et al. 2013). The results of this study show that the students find that the interface is pleasant and they have enjoyed the experience of using it. They feel satisfied with the amount of information available and the organization of the information in the screen. Design students also think that it is easy to learn to use the IT tool and that it is fine to develop a creative design task in virtual teams. However, students think that the assigned design task is more difficult to do in virtual teams and that it can be solved in a better and faster way in face-to-face teams. A $30 \%$ of the students have felt 
equally satisfied, but a $46 \%$ have felt more satisfied in the face-to-face. As a conclusion of the study this kind of creative design tasks are more efficient, in the opinion of the students, in face-to-face teams than in virtual teams using chat.

Another possible explanation of the results of the experiment is that by not following any particular design method the designers focused on solving the problem using the means available. That could have been different if they had been required to apply a particular design method, because in that case perhaps the environment would have interfered more significantly. For example, using chat tools versus direct audio communication may slow down the generation of ideas in a brainstorming session. For that reason we decided not to use any particular method, since some methods may be more focused on direct interaction and others may work better with the support of new technologies. As our intention in this study was to analyse the influence of using ICTs, or not, on design results in terms of novelty, usefulness and creativity, not using any methodology to address the design of the proposals makes it possible to eliminate the variable relating to the method. However, previous studies have shown that without a working methodology the scores obtained in these three parameters are generally lower (Chulvi et al. 2012b; Chulvi et al. 2012a), so that it becomes more difficult to appreciate significant differences in the scores from the results of in-person teams and those that used ICTs.

\section{Conclusions}

The main results of the study suggest that the values of novelty, usefulness and creativity of the proposals created by the teams - without using any particular method - do not appear to be strongly influenced by working face-to-face or virtually. This means that the use of ICTs, or not, during the conceptualization process seems not to affect the qualities of the final result. According to Wilcoxon results, it can't be demonstrated that the quality of the results is affected by the working mode related to use or not ICTs. As there is no difference in the results in both working modes, this conclusion can give greater validity to the studies on the improvements that future virtual design applications may have on these parameters. So, the advantages provided by the use of technology can be analysed with the certainty that the improvement in the results will be caused due to the technology by itself, and not by the reactions of the design teams by using technologies.

Furthermore, as noted above, previous studies have shown that the design methodology affects the levels of novelty, usefulness and creativity of the results (Chulvi et al. 2013; Chulvi et al. 2012a). That is why it will also be useful to know whether certain types of design methods are better for face-to-face working or produce better results when used with virtual teams. Knowing this information would also be useful when developing new virtual work applications for design teams.

Therefore a subject of interest for this study in the short term focuses on comparing the effect of the design methodology to be applied in physical and virtual teams in order to see whether there is any interaction between methodology and working mode (in person or virtual). On the other hand, the work to be carried out in the medium or long term would be to create a virtual tool to assist designers in their 
work remotely, by using methodologies that have previously been shown to be more effective for this purpose.

Moreover, in the results obtained it has also been noticed that the motivation to solve the problem might have an influence on the creativity of the results. However, by not considering this possibility in the initial hypothesis we have not collected enough data in this experiment to analyse whether this factor is really influential. Therefore it would be interesting to perform an experiment in the future based on this new hypothesis, as well as testing whether there could be a significant interaction between personal motivation and in-person or virtual work modes.

\section{References}

Adenauer J, Israel JH, Stark R (2013) Virtual Reality Technologies for Creative Design. CIRP Design 2012. pp. 125-135. Springer London

Andres HP (2002) A comparison of face-to-face and virtual software development teams. Team Performance Management 8(1/2):39-48

Ardaiz-Villanueva O, Nicuesa-Chacón X, Brene-Artazcoz O, Sanz de Acedo Lizarraga, María Luisa, Sanz de Acedo Baquedano, María Teresa (2011) Evaluation of computer tools for idea generation and team formation in project-based learning. Comput Educ 56(3):700-711.

Atman CJ, Cardella ME, Turns J, Adams R (2005) Comparing freshman and senior engineering design processes: an in-depth follow-up study. Des Stud 26(4): 325-357.

Chulvi V, Mulet E, Gonzalez-Cruz MC (2012) Medida de la creatividad en productos: Métricas y objetividad. Dyna 87(1):80-89

Chulvi V, Mulet E, Chakrabarti A, López-Mesa B, González-Cruz C (2012a) Comparison of the degree of creativity in the design outcomes using different design methods. J Eng Des. 23(4): 241-269

Chulvi V, Sonseca Á, Mulet E, Chakrabarti A (2012b) Assessment of the Relationships Among Design Methods, Design Activities, and Creativity. Journal of Mechanical Design 134(11): 111004

Chulvi V, González-Cruz MC, Mulet E, Aguilar-Zambrano J (2013) Influence of the type of ideageneration method on the creativity of solutions. Research in Engineering Design. 24(1): 33-41

De Pillis E, Furumo K (2007) Virtual vs. Face-to-Face Teams: Deadbeats, Deserters, and Other Considerations. In Proceedings of the 2006 ACM SIGMIS CPR conference on computer personnel research: Forty four years of computer personnel research: achievements, challenges $\backslash \&$ the future (SIGMIS CPR '06). ACM, New York, NY, USA, 318-320.

Flowers J (2001) Online learning needs in technology education. Online Learning 13(1) 
Grabska E (2012) Towards a Formal Model of Visual Design Aided by Computer. In: Anonymous Human-Computer Systems Interaction: Backgrounds and Applications 2, Springer, pp 135-147

Groover M, Zimmers E (1983) CAD/CAM: computer-aided design and manufacturing. Prentice Hall Gundy A (1981) Techniques of structured problem solving. NY: Litton Educational Publishing

Howard T J, Culle, S.J, Dekoninck E (2008). Describing the creative design process by the integration of engineering design and cognitive psychology literature. Design studies, 29(2): 160-180.

Jezernik A, Hren G (2003) A solution to integrate computer-aided design (CAD) and virtual reality (VR) databases in design and manufacturing processes. The International Journal of Advanced Manufacturing Technology 22(11-12): 768-774

Jones JC (1980) Design Methods: Seeds of human futures. 1980 ed

Knapp ML, Hall JA (2009) Nonverbal communication in human interaction. Wadsworth Publishing Company

Kratzer J, Leenders RTA, Van Engelen JM (2006) Managing creative team performance in virtual environments: an empirical study in 44 R\&D teams. Technovation 26(1): 42-49

Kudrowitz BM, Wallace D (2012) Assessing the quality of ideas from prolific, early-stage product ideation Journal of Engineering Design, 24(2): 120-139

Leenders RTA, Van Engelen JM, Kratzer J (2003) Virtuality, communication, and new product team creativity: a social network perspective. J Eng Technol Manage 20(1): 69-92

Lopez-Mesa B, Mulet E, Vidal R, Thompson G (2011) Effects of additional stimuli on idea-finding in design teams. J Eng Des 22(1): 31-54

MacGregor SP, Torres-Coronas T (2007) Higher creativity for virtual teams: developing platforms for cocreation. IGI Global

Michael, K. Y. (2001). The effect of a computer simulation activity versus a hands-on activity on product creativity in technology education.

Moss J (1966) Measuring creative abilities in junior high school industrial arts. American Council on Industrial Arts Teacher Education

Mulet E, Escamilla N, Chulvi V, Garcia-Garcia C, Felip F, Galán J (2013) Analysis of students opinion about a creative design experience by means of virtual synchronous teams. Proceedings of the 15 th international conference on engineering and product design education, Dublin, Ireland 5 th -6 th September 2013:126 
Ocker RJ (2005) Influences on creativity in asynchronous virtual teams: a qualitative analysis of experimental teams. Professional Communication, IEEE Transactions on 48(1): 22-39

O'Quin K, Besemer SP (1989) The development, reliability, and validity of the revised creative product semantic scale. Creativity Research Journal 2(4): 267-278

Rahman N, Cheng R, Bayerl PS (2012) Synchronous versus asynchronous manipulation of 2D-objects in distributed design collaborations: Implications for the support of distributed team processes. Des Stud 34(3), 406-431

Regli WC (1997) Internet-enabled computer aided design. Internet Computing, IEEE 1(1): 39-50 Rivera J, Vidal R, Chulvi V, Lloveras J (2010) La transmisión visual de la información como estímulo cognitivo de los procesos creativos. Anales de Psicología 26(2), 226-237

Sarkar P, Chakrabarti A (2008) Studying Engineering Design Creativity-Developing a Common Definition and Associated Measures Australia: Springer Verlag

Sarkar, P., \& Chakrabarti, (2014) A. Ideas generated in conceptual design and their effects on creativity. Research in Engineering Design, 25(3): 185-201

Seichter H (2003) Augmented reality aided design. International Journal of Architectural Computing Shah, J. J., Smith, S. M., \& Vargas-Hernandez, N. (2003). Metrics for measuring ideation effectiveness. Design studies, 24(2), 111-134.

Shigeki A, Zafer B (2008) Our Content: generative montage methods for multimedia data Design Studies, 29(6): 572-586

Smyth, P. S. (2010). Planning Purposeful Imaginative Activities in Creative Contexts for Children's Literacy (Doctoral dissertation, Cranfield University).

Stricker, D. R. (2008). Perceptions of creativity in art, music and technology education. ProQuest.

Tang H, Lee Y, Gero J (2011) Comparing collaborative co-located and distributed design processes in digital and traditional sketching environments: A protocol study using the function-behaviour-structure coding scheme. Des Stud 32(1): 1-29

Thompson G, Lordan M (1999) A review of creativity principles applied to engineering design. Proc Inst Mech Eng Part E J Process Mech Eng 213(1): 17-31.

Van der Lugt R (2002) Functions of sketching in design idea generation meetings Proceedings of the 4th conference on Creativity \& cognition. ACM, pp. 72-79.

Warkentin M, Sayeed L, Hightower R (1997) Virtual Teams versus Face-to-Face Teams: An Exploratory Study of a Web-based Conference System. Decision Sciences, 28(4): 975-996. 
Yu J, Krizan S, Ishii K (1993) Computer-aided design for manufacturing process selection. J Intell Manuf 4(3): 199-208 